\title{
Ainda somos o país do futebol? Uma análise discursiva do The New York Times na cobertura da Copa do Mundo da FIFA 2014
}

\author{
Are we still the football country? \\ A discursive analysis of The New York Times \\ at the World Cup 2014 FIFA coverage
}

\begin{abstract}
Gabriel de Lima Alves Cortez | Universidade Estadual Paulista Júlio de Mesquita Filho (Unesp) Mestrando no Programa de Pós-graduação em Comunicação da Faculdade de Arquitetura, Artes e Comunicação da Universidade Estadual Paulista (UNESP/Bauru) e integrante do GE-CEF (Grupo de Estudos em Comunicação Esportiva e Futebol)

E-mail: gabrielcortez@faac.unesp.br
\end{abstract}

José Carlos Marques | Universidade Estadual Paulista Júlio de Mesquita Filho (Unesp) Docente do Programa de Pós-Graduação em Comunicação da Faculdade de Arquitetura, Artes e Comunicação da Universidade Estadual Paulista (UNESP/Bauru) e Líder do GECEF (Grupo de Estudos em Comunicação Esportiva e Futebol) E-mail: zeca.marques@faac.unesp.br

\section{Resumo}

Este artigo aborda as relaçôes entre o esporte, a comunicação e a cultura por ocasião da Copa do Mundo da FIFA 2014, realizada no Brasil entre junho e julho daquele ano. Analisaremos o discurso do jornal norte-americano The New York Times, a fim de identificar a maneira com que o periódico retratou esse evento em suas páginas. Nossa abordagem procurará verificar se um dos mais prestigiados jornais estrangeiros reproduz determinadas formas recorrentes de construção da identidade brasileira, as quais apontariam para um "estilo brasileiro de jogar futebol" (conceito fundado por Gilberto Freyre) ou para a ideia de que o Brasil seria "o" "País do futebol", lugares-comuns que vêm sendo estabelecidos por uma perspectiva de brasilidade essencialista e homogeneizadora.

Palavras-Chave: Copa do Mundo FIFA 2014; identidade brasileira; jornalismo norte-americano

\begin{abstract}
This article discusses the relationship between sport, communication and culture on the occasion of the FIFA World Cup 2014, held in Brazil in June and July of that year. We analyze the speech of the American newspaper The New York Times, in order to identify the way the newspaper portrayed this event on their pages. Our approach will identify the forms of construction of Brazilian identity by one of the most prestigious foreign newspapers and verify if it has reproduced recurring discourses that would point to a "Brazilian football style" (concept founded by Gilberto Freyre) or the idea that Brazil would be "the football country", commonplaces that have been established by an essentialist and homogenizing perspective.
\end{abstract}

Keywords: FIFA World Cup 2014; Brazilian identity; American journalism 


\section{Esporte moderno, sociedade midiatizada e globalização}

Desde o século XIX, o esporte vem sendo concebido como um fruto do capitalismo e da necessidade liberal de normatizar as relaçóes sociais (DUNNING \& ELIAS, 1985). Neste contexto, as esferas do lúdico e do sagrado - inerentes aos jogos desde os rituais primitivos das sociedades tribais, como apontou o historiador holandês Johan Huizinga (2000) - passaram por um esvaziamento, à medida que o esporte moderno se desenvolveu de maneira racio-nalizada, em meio à Revolução Industrial e à urbanização das cidades (HUIZINGA, 2000). Desde então, as sociedades têm modificado as suas relaçôes com o esporte - sobretudo, a par-tir da década de 1950 do século XX, com o refinamento do aparato tecnológico comunicacional e, de sobremaneira, com a evolução das transmissôes esportivas televisivas.

Sob esta perspectiva, os meios de comunicação passaram a estabelecer uma relação de mútua alimentação - ou de "integração" (TUBINO, 1999, p. 29) - com os esportes modernos - relação que se fortalece a partir de uma discursivização dos esportes pelos veículos de co-municação, ou seja, a partir do agendamento, da cobertura, da "narrativização" (COSTA, 2016) e da repercussão dos eventos esportivos pelos meios de comunicação de massa (ALVAREZ, 2013, p. 6); uma relação da qual ambos (mídia e esporte) se beneficiam e com a qual ambos (esporte e mídia) buscam resultados mais satisfatórios, tanto em aumento de audiência, quanto em aumento de torcedores. Por fim, uma relação a qual se evidencia em períodos de megaeventos esportivos, como uma Copa do Mundo de Futebol (AMARO, MOSTARO \& HELAL, 2014, p. 9).

Neste artigo, buscaremos analisar a maneira com que os discursos de um dos jornais mais influentes do planeta, o diário norte-americano The New York Times, opera as suas nar-rativas na cobertura de um megaevento esportivo contemporâneo de consumo global (e, obvi-amente, de alto rendimento) como uma Copa do Mundo de Futebol. Nomeadamente, analisa-remos com base em conceitos da Análise do Discurso Francesa (BENVENIESTE, 1989; CHARAUDEAU \& MAINGUENAU, 2006; DUCROT, 1987) - a cobertura da Copa do Mundo de Futebol de 2014 realizada por The New York Times e publicada na versão online do jornal (nytimes.com), entre os dias 8 e 15 de julho de 2014, a fim de diagnosticar a maneira com que os discursos do periódico trabalharam - reforçaram ou ressignificaram - o epíteto "Brasil: país do futebol".

Para tanto, será necessário revisitar as discussóes acerca do tratamento dado pela im-prensa e pela sociedade a este aspecto "imaginado" (no sentido que Benedict Anderson em-prega ao termo) do Brasil e do futebol brasileiro: isto é, seríamos, ainda, "o país do futebol"? Como a imprensa estrangeira trabalha com esta construção discursiva - em especial, na cober-tura de um Mundial de Futebol? Como se deu essa "discursivização", por parte de um veículo de comunicação estrangeiro, acerca do Brasil e do futebol brasileiro? 


\section{Jornalismo, megaeventos esportivos e lugares-comuns}

A cobertura de um megaevento esportivo - ou uma reportagem acerca de uma figura ou de uma entidade esportiva (como um jogador ou uma seleção de futebol) - é um espaço em que, além de "fatos", "imaginaçóes” se disseminam. Isto porque, nas palavras de Manoel Tu-bino, "para alcançar o sucesso, a manifestação esportiva precisa de ídolos, os chamados 'deu-ses dos estádios', e de grandes espetáculos [...] evidenciando detalhes de grande interesse para o público, como as emoçóes, os fatos paralelos, os bastidores e tudo que possa causar sensa-ção" (TUBINO, 1999, p.31).

Sob esta perspectiva, é preciso lembrar que a imprensa busca lugares-comuns (os topoi aristotélicos) para falar dos acontecimentos, uma vez que:

[...] os repórteres são 'contadores de histórias' (TUCHMAN, 1999, p.261), sendo que essas histórias são compostas levando-se em consi-deração as especificidades do meio jornalistico. [...] Na elaboração de sua narrativa há interferência da rotina dos meios de comunicação, pautadas pelo curto tempo e a necessidade de se recorrer a fórmulas narrativas de fácil entendimento, sem linguagem rebuscada, o que im-plica formas convencionais de se produzir as notícias (SCHUDSON, 1999). Nesse sentido, teríamos uma porta aberta para se unir informa-ção e imaginação com objetivo de cativar o público, ou seja, a audiência. Imaginação melodramática (BROOKS, 1995), pois que marcada pelo exagero, por lugares-comuns e conteúdos eivados de convencionalismo para alcançar um público massivo. (COSTA, 2016, p. 123)

Assim, o jornalismo constrói e reconstrói a realidade por meio de seus discursos. Cria narrativas, identidades e diferenciaçóes. Estabelece ídolos, heróis e mitos. Fabrica vilóes e celebridades. Humaniza atletas e torcedores e, desta forma, além de informar, busca causar "sensaçôes" em seu público a fim de entretê-lo e de cativá-lo:

[...] a emoçâo é elemento central na composição da notícia esportiva, daí reportagens
marcadas pelo excesso verbal, por polêmicas e espe-culaçôes. Os jogos são convertidos em
histórias repletas de dramatiza-çôes em que o tom superlativo prepondera na tentativa
de provocar os afetos do leitor, fomentando identificaçáo fácil e imediata. É com ob-
jetivo de obtençâo de boas médias de vendagem que a imprensa espor-tiva costuma
lançar máo de recursos narrativos, especialmente os me-lodramáticos e folhetinescos,
cuja intensidade pode variar de acordo com o tipo de publicação. Por isso, há também
um forte diálogo com a linguagem publicitária perceptivel em manchetes próprias para
incita-rem o consumo. (COSTA, 2010, p.72)

Deste modo, interessa observar que "grande parte da cobertura da imprensa esportiva é res-paldada pelos receptores de suas mensagens, o que significa dizer que muito do que ela produz responde a nossas próprias expectativas" (COSTA, 2010, p.72). Neste sentido, pode-se dizer que as narrativas esportivas delineiam-se oportunas aos profissionais da imprensa, oferecendo-se a eles e, em um segundo momento, aos leitores - como a bola que se insinua ao centroavante goleador.

Nesta relação, os esportes - assim como o jornalismo - constituem-se em espaços de construção mitológica, de criação de identidades, e de produção de sensaçôes, pois que carre-gam valores e encerram sentido: 
O jogo é mais do que um fenômeno físico ou um reflexo psicológico. Ultrapassa os limites da atividade puramente física ou biológica. É uma função significante, isto é, encerra um determinado sentido. No jogo, existe algo 'em jogo' que transcende as necessidades imediatas de vida e confere um sentido à ação. Todo jogo significa alguma coisa. [...] o simples fato de o jogo encerrar um sentido implica a presença de um elemento náo material em sua própria essência. (HUIZINGA, 2000, p. 4)

Uma vez, portanto, que esporte e mídia operam em conjunto, importa-nos verificar como se dá a construção discursiva da imprensa na cobertura de um megaevento esportivo como uma Copa do Mundo de Futebol. Especificamente, como o jornalismo internacional constrói "sentidos", atribui "valores" e reproduz lugares-comuns em seus discursos a respeito de um país sede de um espetáculo esportivo global? Objetiva-se, desta forma, identificar quais identidades brasileiras aparecem nos relatos de The New York Times acerca do Brasil, do fute-bol brasileiro, e de seus habitantes e, neste sentido, indicar quais lugares-comuns são (re)produzidos e quais discursos são pressupostos e subentendidos (DUCROT, 1987) como símbolos da "nação" e de um "ser" brasileiro.

\title{
Os esportes nacionais e os lugares-comuns: ainda somos o "país do futebol"?
}

Roland Barthes, no ensaio "O que é esporte?" (1961), lembra que um "esporte nacio-nal" é um esporte que "brota da própria matéria da nação" (p. 103). O futebol, apesar de não brotar "da própria matéria da nação" brasileira, chega às vias de ser considerado um "esporte nacional":

\begin{abstract}
Embora tenha sido formalizado e estruturado por meio de regras uni-versais na segunda metade do século XIX, na Inglaterra, o futebol não demorou a ser adotado pela população brasileira como uma modalidade esportiva praticada por individuos de diferentes classes sociais, fe-nômeno que ganhou corpo especialmente ao longo das décadas de 1920 e 1930, como mostram estudos acadêmicos de José Sérgio Leite Lopes (1998), Waldemir Caldas (1990) e Fábio Franzini (2003), ou contribuiçóes históricas como as de Thomas Mazzoni (1950) e Bill Murray (2000). Ao longo dos anos, esta modalidade tornou-se cultu-ralmente característica de um ethos brasileiro, tanto na visão da popu-lação nacional como estrangeira, tese defendida pelo antropólogo Roberto DaMatta. (MARCONDES \& MARQUES, 2016, p.135)
\end{abstract}

Neste contexto, o Brasil, em muitos discursos, é referenciado como "o" "país do fute-bol", seja por autores da historiografia nacional, por reportagens jornalísticas ou por textos da academia:

Repetido diversas vezes e vendido para o exterior como uma das ima-gens que melhor representa o nosso pais, o epiteto 'Brasil: pais do fute-bol' merece uma investigação cuidadosa. Ele contém uma expressiva força simbólica que contribui para a construção de nossa identidade. In-ternamente, utilizamos, quase sempre, com um viés positivo, como uma maneira de nos sentirmos membros de uma nação singular, mas alegremesmo diante de evidências que nos levam a especular ser essa singula-ridade mais global do que se imagina, e ainda diante da diminuição do impacto que as vitórias e as derrotas da nossa seleção vêm trazendo para a sociedade. (HELAL, 2014, p. 18) 
O sociólogo Gilberto Freyre, em "Foot-ball Mulato" (1938), apresentou as bases a esta concepção de Brasil como o "país do futebol" - sobretudo, país do "futebol-arte" (LOVISO-LO \& PEREIRA, 2014, p. 37) - quando propôs um "estylo brasileiro de jogar" e comparou este "estylo brasileiro", em campo, a um estilo de "ser brasileiro" fora de campo - bem como a uma "formação social democrática" brasileira "como nenhuma" (isto é, "única” e diferente de uma alteridade estrangeira). Assim, Freyre apontava "o" brasileiro - a partir de uma pers-pectiva essencialista e homogeneizadora - como um "ser" (utiliza-se, aqui e na próxima cita-ção, a grafia original do texto de Freyre):

Rebelde a excessos de ordenação interna e externa; a excessos de uni-formisação de geometrisação, de standardização; a totalitarismos que façam desaparecer a variação individual ou espontaneidade pessoal. No foot-ball como na politica, o mulatismo brasileiro se faz marcar por um gosto de flexão, de surpresa, de floreio que lembra passos de uma dansa e de capoeiragem. Mas sobretudo que permita o improviso, a diversidade, a espontaneidade individual (FREYRE, 1938, p. 4).

No mesmo texto, o autor compara o "estylo" brasileiro ao "estylo" europeu de jogar futebol:

O nosso estylo de jogar foot-ball me parece contrastar com o dos eu-ropeus por um conjunto de qualidades de surpresa, de manha, de astu-cia, de ligeireza e ao mesmo tempo de espontaneidade individual em que se exprime o mesmo mulatismo de que Nilo Peçanha foi até hoje a melhor afirmação na arte política. Os nossos passes, os nossos pitu's, os nossos despitamentos, os nossos floreios com a bola, o alguma coisa de dansa e de capoeiragem que marca o estylo brasileiro de jogar foot-ball, que arredonda e adoçava o jogo inventado pelos ingleses e por eles e por outros europeus jogado tão angulosamente. [...] O mulato brasileiro deseuropeisou o foot-ball dando-lhe curvas, arredondados e graças de dansa. Foi precisamente o que sentiu o cronista europeu que chamou os jogadores brasileiros de "bailarinos" da bola. Nós dansamos com a bola. (FREYRE, 1938, p. 4).

Desta maneira, o texto de Freyre inaugura uma ideia de contraposição, via futebol, da identidade brasileira a uma identidade estrangeira (futebol dionisíaco brasileiro x futebol apo-líneo europeu) e "funda" (GUEDES, 2014, p. 156; MARANHÃO, 2006) uma noção que se tornaria frequente nos textos jornalísticos nacionais e estrangeiros acerca do Brasil e do futebol brasileiro (sobretudo, a respeito da seleção nacional em períodos de Copa do Mundo):

O 'pais do futebol' foi uma construção social realizada por jornalistas e intelectuais em um momento de consolidação do estado-nação, acompanhada por formulaçôes acadêmicas sobre a sociedade. Foi a partir do anos 1930 que se apresentaram novas formas de conceituar o país. Se antes, pelas lentes de um acadêmico como Francisco de Oli-veira Viana (1883-1951), a miscigenação racial era vista como 'atraso' do pais, a partir da obra clássica de Freyre (1900-1997) Casa Grande e Senzala [e, no que tange ao futebol, a partir do texto Foot-ball Mulato], a mistura passa a ser entendida como um valor positivo e força maior da população brasileira. (HELAL, 2014, p. 21) 
Porém, autores como o citado Ronaldo Helal, Antônio Jorge Soares (2002) e Hugo Lovisolo indicam a tendência a um arrefecimento desta noção de Brasil como a "pátria do futebol":

Ao contrário de décadas atrás, hoje seria lícito perguntar se o Brasil estaria deixando de ser o 'país do futebol'. [...] suspeitamos que a ten-dência da globalização da cultura em curso, que teve nos esportes um veículo de encontro, de apropriaçóes entre os diferentes estados-naçóes, estaria transformando a identidade nacional, sintetizada como narrativa homogênea na 'pátria de chuteira'. [...] Esse processo de des-territorialização do idolo e do futebol cria um novo processo de iden-tidade cultural. [...] As vitórias e as derrotas da seleção em copas do mundo produzem celebraçôes e tristezas coletivas. No entanto, não são mais vividas como vitórias ou derrotas de um projeto de nação brasileira. Nesse sentido, não somos mais o 'país do futebol' como décadas atrás e a seleção não é mais a 'pátria de chuteiras' nos moldes de Nelson Rodrigues. Isso não é ruim, nem bom. Simplesmente é. (HELAL, 2014, p. 21)

Neste contexto, cabe questionarmo-nos: como o jornalismo estrangeiro opera os seus discursos a respeito de um "Outro" país, isto é, de sua alteridade? Quais "lugares-comuns" são reforçados? Quais narrativas se criam? Ou seja: somos, ainda, "o" "país do futebol" aos olhos dos jornalistas de The New York Times? E mais: de que forma o periódico noticiou a mais expressiva - ao menos em números - derrota do selecionado brasileiro em copas do mundo de futebol? É o que pretendemos observar no tópico seguinte, buscando compreender a maneira com que o diário norte-americano descreveu a reta final da Copa 2014 momento no qual, em maior ou menor grau, é feito um "balanço" do evento por parte dos jornalistas da imprensa global. Por este motivo, o corpus de pesquisa deste artigo compreende as reportagens publicadas em nytimes.com na semana em que ocorreu a derrota da seleção brasileira para a seleção alemã e o último jogo do torneio - especificamente, entre os dias 08 e 14 de julho de 2014.

\section{O Discurso de The New York Times na cobertura da Copa do Mundo da FIFA 2014}

Em reportagem [Goal, Goal, Goal, Goal, Goal, Goal, Goal, Brazil's Day Goes Dark] publicada no site nytimes.com, no dia 08 de julho de 2014, poucas horas após a vitória da se-leção alemã sobre a seleção brasileira, por 7 a 1, pela semifinal do Mundial, o jornalista de The New York Times, Sam Borden, oferece indícios de como o diário norte-americano construiu os seus discursos a respeito do megaevento organizado no Brasil e, sobretudo, de como os jornalistas do periódico narraram a derrota do selecionado brasileiro para os alemães:

BELO HORIZONTE, Brasil-Os fogos de artificio começaram ao amanhecer. Tudo ao redor da cidade, altos estouros e barulhos repen-tinos de homens, mulheres e crianças, muitos deles vestidos de ama-relo, iniciavam o arroubo e as buzinas em seus carros. Era para ser um dia mágico. A seleçấo nacional brasileira de futebol, jogando em casa, estava a um jogo da final da Copa do Mundo. Mas, ninguém poderia esperar que as lágrimas viriam antes do intervalo. [...] A Copa do Mundo 2014, primeiramente atormentada por questóes de financia-mento, infraestrutura e protestos, impulsionada 
por muitos gols, finais dramáticos e um contagiante espirito de alegria dos residentes locais, será, por último, lembrada por isto: o time da casa, considerado como a superpotência mundial do esporte [futebol], sendo estrangulado como um esquadrão juvenil que alguém, por um lapso, colocou no jogo errado.(BORDEN,2014a). ${ }^{1}$

Em uma primeira análise, percebe-se que o texto de The New York Times, assinado por Sam Borden, apresenta a seleção brasileira como se a instituição fosse - até o "estrangula-mento" [throttled] imposto pela seleção alemã - considerada "a" super potência do futebol mundial [the home team, regarded as the sport's super power]. Ao mesmo tempo, o jornalista denota surpresa ante ao placar elástico do jogo, o qual, segundo Borden, seria lembrado [will ultimetaly be remebered] como a última memória do megaevento, em meio a uma copa a qual havia sido marcada, de início, por questionamentos sobre infraestrutura, gastos excessivos e protestos na ruas, mas, que, ainda assim, agradava até então, pela alegria dos "brasileiros" fora de campo [a contagious spirit of joy from the local residentes] e pelo bons jogos em campo [buoyed by scads of goals and dramatic finishes].

Desta maneira, quando o autor da reportagem fala em um "contagiante espírito de ale-gria dos residentes locais", explicita (e, direta ou indiretamente, reforça ao olhar estrangeiro) uma visão historicamente estereotipada de um "ser" brasileiro cordial e hospitaleiro. Contudo, na sequência do texto, o jornal denota preocupação com a segurança no país após o "massacre" alemão [a soccer massacre of highest order], apresentando-se, portanto, de maneira implícita (DUCROT, 1987), uma aparente contradição entre as características de cordialidade e de hostilidade atribuídas aos "residentes locais" (grifos nossos, em itálico):

O placar final foi Alemanha 7, Brasil 1. Mais parecia Alemanha 70, Brasil 1. [...] "Eu acho", disse [Luiz Felipe] Scolari após o jogo, "que foi o pior dia da minha vida". Ele, certamente, não estava sozinho na-quele sentimento. Os esportes são sempre cheios de hipérboles, mas havia risco no que ocorreu aqui na terça-feira. Dadas as circunstâncias e as apostas, o resultado - um massacre futebolistico da mais alta ordem - pode muito bem ser lembrado como o mais surpreendente na história das Copas do Mundo. [...] "Foi a maior vergonha de todos os mundiais - 7 a $1 \mathrm{em}$ uma semifinal jogando em casa?", disse Marcel Guimarães, 38, que veio de Brasília a Belo Horizonte. "Nem mesmo em uma partida de vídeo game". O rescaldo da derrota do Brasil poderia ser feio. Houve relatos de um roubo em massa em uma fan party no Rio de Janeiro e fäs incendiando bandeiras do Brasil nas ruas de São Paulo. Organizadores locais e funcionários do governo têm se preocupado há semanas com a possibilidade de que as manifestaçóes - que, em sua maior parte, ficaram diminuidas - se tornassem mais intensas se o Brasil fosse eliminado. Muitos brasileiros estão revoltados com os bilhóes de dólares gastos em novos estádios e em outros projetos relativos à Copa do Mundo. O sucesso da seleção nacional ofereceria uma calmaria natural, mas agora essas emoçôes podem ser inflamadas. [...] Scolari encolheu os ombros e se arrastou para fora da sala de imprensa cabisbaixo por um corredor estreito. Os fogos de artifício ao amanhecer pareciam tão distantes. Eles tinham sido um indicativo inicial, um começo animado de um dia que os brasileiros esperavam lembrar para sempre. Então, veio um rolo compressor alemão e um jogo que a nação de fãs do futebol só pode esperar esquecer (BORDEN, 2014a). ${ }^{2}$ 
Nota-se, então, que o texto de The New York Times - quando se refere ao futebol - "enxerga" os "brasileiros" como uma "nação de fấs do futebol" [a soccer fans nation]. Esta visão aproxima-se, por conseguinte, da metonímia essencialista e homogeneizadora segundo a qual o Brasil (como um todo) seria "o" "país do futebol", pressupondo-se, desta forma, que a "nação de fãs do futebol" (composta por "todos" os brasileiros, sem exceção) só esperaria, um dia, esquecer [can only hope to forget] a derrota para os alemães. Assim, em um nível implícito do discurso (DUCROT, 1987), o texto reforça uma questionável ideia, por seu caráter es-sencialista e homogeneizador, de Brasil como a "pátria de chuteiras". De todo modo, esse discurso essencialista é minimizado no momento em que o jornal se refere, especificamente, a uma parcela da população brasileira a qual havia se irritado com os "bilhóes de dólares gastos em novos estádios de futebol e em projetos relacionados ao Mundial" [Many Brazilians have been upset about the billions of dolars spent on new stadiums and other World Cup-related projects]. Neste trecho, por conseguinte, o discurso do jornalista de $N Y T$ se aproxima de uma visão menos distorcida da realidade brasileira: uma sociedade plural e intercultural, na qual convivem diversos grupos sociais em relaçóes de conflito e de negociação constantes - consti-tuída por diversos "Brasis" em um único país.

Em outra reportagem acerca da partida Brasil e Alemanha, 29 Minutes That Shook Brazil (29 Minutos que chocaram o Brasil), publicada em nytimes. com no dia 09 de julho de 2014, o jornalista do diário norte-americano, Sam Borden, nos primeiros parágrafos do texto, compara a derrota dos jogadores brasileiros do dia anterior ( 08 de julho de 2014 ) à derrota da seleção brasileira de 1950, para o Uruguai:

Aqueles 29 minutos serão examinados minuciosamente por geraçóes no Brasil, dissecados do mesmo modo que a derrota do Brasil para o Uruguai na final da Copa de 1950. Moacir Barbosa, o goleiro brasileiro daquela infame partida, disse, antes de morrer, em 2002, que desde então aquele jogo o fez sentir como se tivesse passado o resto da vida na prisäo. A cela apenas ficou mais cheia. Todos os jogadores de ca-misa amarela na terça-feira [08 de julho de 2014], muitos deles su-perstars, serão, acima de tudo, definidos - e aprisionados - por aqueles 29 minutos (BORDEN, 2014b). ${ }^{3}$

Revela-se, neste trecho, a utilização de um discurso conotativo (quase jocoso) por parte do jornalista de The New York Times, o qual compara o sofrimento do goleiro Barbosa, o "viláo" (COSTA, 2008) de 1950, ao sofrimento com o qual lidariam, dali em diante, os "vi-lóes" da derrota para Alemanha [every player in yellow jersey]. Assim, Borden sugere que a "cela" da "prisão" em que Barbosa foi colocado, após a derrota para o Uruguai, apenas ficaria mais cheia com os 7-1 para a Alemanha [That cell just go more crowded]. Após esta introdu-ção, dotada de uma intertextualidade explícita, na qual o jornalista (enunciador) recorreu a uma memória do futebol brasileiro para ilustrar o início do texto, a reportagem descreve os cinco gols do selecionado alemáo, marcados nos primeiros vinte e nove minutos de jogo, a partir dos pontos de vista de brasileiros em diferentes cidades e realidades do país (inclusive, no estádio em que a partida ocorreu). O texto constrói, a partir das falas dos entrevistados - em uma aparente busca por um distanciamento de uma linguagem 
conotativa e por um "apagamento" da subjetividade inerente a todo e qualquer discurso (CHARAUDEAU; MAINGUENEAU, 2006, p. 71) -, uma narrativa que começa esperançosa, mas, termina em tom de incredulidade:

O jogo começou com grandes expectativas. Quando a música do hino nacional parou após os 90 segundos regulamentares, os fäs brasileiros continuaram cantando com vigor, em uma vibrante capela. Porém, a Alemanha marcou o primeiro cedo. "Eu pensei que fossem só os pri-meiros dez minutos, nós ainda tínhamos todo o jogo pela frente", disse Gisleine Pedroni, uma estudante de marketing que assistiu a partida no churrasco de um amigo em São Paulo. José Brito Lopes, que assistiu em um bar em uma favela no Rio de Janeiro onde trabalha, estava calmo. "Quando o primeiro gol aconteceu, eu pensei que aquilo fosse normal, porque a Alemanha estava jogando bem”, ele disse. Alguns, porém, já tinham um sentimento de pavor. Os pelos no pescoço arre-piados. O nó no estômago. "O Brasil não pode perder o foco, eles têm de se concentrar", pensou Susana Osako, uma modelo que assistiu ao jogo com o marido em São Paulo. [...] Há essa hora [momento do se-gundo gol da Alemanha], o estádio estava mais calado. Dois gols em 23 minutos não eram necessariamente uma causa para pânico, mas eram dolorosos. Algumas lágrimas podiam ser vistas nos rostos na ar-quibancada. [...] Marcelo, uma estrela da defesa do Brasil, cobria o rosto com as mãos. Na arquibancada, a dor deu lugar a algo mais, algo estranho. "Nós começamos a rir da situação", disse Felipe Seligman, 30, que estava vestindo a mesma jaqueta e o mesmo shorts que usa to-da vez que o Brasil joga. "Nós estávamos dizendo, 'Oh meu deus, o que está acontecendo? É real?" ". O quinto gol foi quando Machado se afastou da tela. "Eu continuei ouvindo o jogo, ouvindo apenas porque eu não podia mais ver aquilo", ele disse. Três gols em quatro minutos. Quatro gols em seis minutos. Cinco gols em 29 minutos. Um país não conseguia acreditar no que estava ocorrendo (BORDEN, 2014b). ${ }^{4}$

Verifica-se, neste excerto, uma busca "subentendida" - na acepção de Oswald Ducrot (DUCROT, 1987) - por uma pretensa objetividade da narrativa jornalística, no momento em que a reportagem é construída, sobretudo, com base em citaçóes diretas das falas dos entrevis-tados. Todavia, em trechos nos quais a "voz" do jornalista se "coloca" no que está dito (isto é, explícito) no texto, antes ou depois das falas dos entrevistados, é possível que se "pressupo-nha” - também na acepção de Oswald Ducrot - a subjetividade (isto é, a marca de enunciação) inerente a todo e qualquer discurso e, obviamente, também, ao discurso do jornalista de NYT, como ocorre no trecho "Three goal in four minutes. Four goal in six minutes. Five goals in 29 minutes. One country could not believe what had just happened" - trecho o qual aparece, justamente, após uma série de citações de falas dos entrevistados que corroboram com os sentidos produzidos pela narrativa do enunciador, implícita ou explicitamente. Essa estratégia discursiva de apagamento da subjetividade, aliás, revela-se em outros momentos da cobertura do Mundial 2014 realizada pelos jornalistas do periódico norte-americano (como ainda se poderá notar adiante).

Sob essa perspectiva, percebe-se o tom de surpresa com o qual a derrota do "país do futebol" para os alemães, em campo, foi retratada nos excertos jornalísticos de The New York Times. Entretanto, do ponto de vista "extracampo", o mundial no Brasil foi avaliado positi-vamente pelo jornal neste momento final de cobertura. Em texto opinativo publicado no dia 14 de julho de 2014 
(Cleaning Up After World Cup), o corpo editorial (Editorial Board) de NYT enaltece o sucesso da Copa do Mundo no Brasil (a qual se encerrara um dia antes, em 13 de julho de 2014) e afirma que o país (e, metonimicamente, o seu povo) poderia ficar orgulhoso do megaevento - “exceto, é claro," pela derrota, em campo, na semifinal:

O Brasil pode ficar orgulhoso pela Copa do Mundo que realizou - ex-ceto, é claro, pelo apagão chocante de sua seleção na derrota para a Alemanha, na semifinal, por 7 a 1. As multidóes estavam coloridas, alegres e bem comportadas, e os jogos variavam do entretenimento ao brilhantismo, todos devorados por um público recorde na televisão e nas mídias sociais. Houve ligaçôes duvidosas, fracasso estrondoso e a bizarra mordida de Luiz Suárez, mas o perfeito gol de Mario Gotze, que deu a Copa à Alemanha, é o mais preciso icone do torneio de qua-tro semanas e meia. Como um todo, a Copa do Mundo demonstrou porque o futebol é o mais global e popular dos esportes. E porque é hora de a Fifa avaliar melhor o esporte que governa. [...] O futebol é uma força importante no mundo de hoje. Ela deveria fazer o possivel para mantê-lo limpo, seguro e justo (Nytimes.com, 2014).5

\section{Considerações finais}

A cobertura da reta final da Copa do Mundo da FIFA 2014 de The New York Times apresentou, portanto, um tom de surpresa quanto ao desempenho da seleção brasileira, em campo, bem como em relação ao "desempenho" dos "brasileiros" fora de campo. A equipe, segundo o jornal (em uma aproximação interdiscursiva das ideias de Gilberto Freyre, em "Foot-ball Mulato"), não conseguiu executar o seu "tradicional" "jogo bonito" [it's traditional beautiful game] durante as partidas da competição e, ainda por cima, foi eliminada na semifinal do torneio, em um "massacre" histórico, o qual não sairá da memória dos torcedores da seleção nacional. A propósito, esses torcedores [a nation of soccer fans] foram apresentados pelos jornalistas de The New York Times de forma generalista e homogeneizadora, como se "todos" os "brasileiros", sem exceção, fossem apaixonados pelo esporte no país.

O tom de surpresa do jornal em relação ao futebol do selecionado brasileiro, em campo, mostra como uma visão de Brasil como o "país do futebol", de fato, pode estar com os dias contados - fenômeno aventado por autores como o sociólogo do esporte Ronaldo Helal desde o início do século XXI. Apesar disso, como se pôde notar na cobertura de $N Y T$, este discurso ainda figura - implícita ou explicitamente, direta ou indiretamente - na visão de parte da imprensa estrangeira a respeito futebol do país. Por isso, não se pode concluir que a derrota para a seleção alemã tenha sacramentado o "fim" do epíteto como um discurso acerca da "nação" brasileira (em um sentido essencialista e homogeneizador do termo nação). Contudo, pode-se dizer que a "certeza" de que o Brasil é "o" "país do futebol" vem se diluindo - inclu-sive, ante ao olhar estrangeiro.

Ademais, do ponto de vista discursivo e textual, é interessante observar como as repor-tagens do veículo norte-americano fizeram uso de adjetivaçôes nos momentos em que se refe-riram à seleção brasileira - sobretudo, nas descrições da partida semifinal do Mundial (Brasil 1 x 7 Alemanha). Em 
contraposição a isso, verificou-se, por parte dos jornalistas de The New York Times, uma busca por um ocultamento da subjetividade do enunciador (expressa pela relaçáo $E u$-Tu) inerente a todo e qualquer formação discursiva e, como não poderia deixar de ser, aos textos dos jornalistas do periódico. Neste sentido, constatou-se uma aproximação dis-cursiva entre os textos informativos/narrativos e os textos opinativos de The New York Times acerca do Mundial de futebol de 2014.

Por fim, deixam-se - a outro momento de pesquisa - as provocaçôes acerca das relaçóes entre os discursos midiáticos, o esporte e o jornalismo esportivo. Haveria uma tendência de integração (em uma possível relação de mútua alimentação) dos fenômenos esportivos com os veículos de comunicação contemporâneos? Como seria a existência de uns sem os outros? Além disso, o que faz dos esportes "mercadorias" atrativas aos mass media? E mais: de que forma os meios de comunicação se apropriam dos espetáculos esportivos de alto rendimento a fim de incrementar a sua audiência? São questóes afeitas a uma próxima reflexão.

\section{Referências bibliográficas}

ALVAREZ, Fábio; MARQUES, José Carlos. Da marginalidade ao mainstream: reflexóes sobre o MMA (Ates Marciais Mistas) e as sociedades capitalistas contemporâneas. E-compós, Brasília, V.16, n.3, set./dez. 2013.

AMARO, Fausto; MOSTARO, Filipe; e HELAL, Ronaldo. Mídia e megaeventos esportivos: as cerimônias de abertura dos Jogos Olímpicos. Revista Logos, Dossiê Megaeventos e espaço urbano. Edição 40, n. 24, v.1, $1^{\circ}$ semestre de 2014.

ANDERSON, Benedict. Comunidades imaginadas: reflexóes sobre a origem do nacionalismo. 4a Reimpressão. São Paulo: Companhia das Letras, 2008.

BENVENIESTE, Emile. Da subjetividade na linguagem. In: BENVENIESTE, Emile. Problemas de linguistica geral I. Trad.: Maria da Glória Novak e Maria Luísa Neri. Campinas, SP: Pontes, 1989.

BARTHES, Roland. Mitologias. 9a edição. Rio de Janeiro: Ed. Bertrand Brasil, 1993.

O que é esporte, em Revista Serrote, no 3, São Paulo: Instituto Moreira Salles, 2009.

BORDEN, Sam. Goal, Goal, Goal, Goal, Goal, Goal, Goal, Brazil's Day Goes Dark, 2014a. Disponível em: <http://www.nytimes.com/2014/07/09/ sports/worldcup/world-cup-2014-host-brazil-stunned-7-1-by-germany-in-semifinal.html>. Acesso em: 28 fev. 2016.

BORDEN, Sam. 29 Minutes That Shook Brazil, 2014b. Disponível em: <http://www.nytimes.com/2014/07/10/sports/world-cup-2014-five-german-kicks-felt-in-brazilian-guts-everywhere.html>. Acesso em: 28 fev. 2016.

CAILLOIS, Roger. Los juegos y los hombres. México: Fondo de Cultura Económica, 1986. 
CORTEZ, Gabriel e MARQUES, José Carlos. A figura dos "brasileiros" no jornalismo de revista nacional: o "vexame" na Copa do Mundo 2014 e a inversão nos discursos da revista Época. In: Anais do XXXVIII Congresso Brasileiro de Ciências da Comunicação da INTER-COM, Rio de Janeiro, 2015. Disponível em: <http://portalintercom.org.br/ anais/nacional2015/resumos/R10-1148-1.pdf>.

COSTA, Leda. A trajetória da queda: as narrativas da derrota e os principais vilóes da seleção brasileira (Tese). UERJ, 2008.

Quem matou o futebol brasileiro? A novela da copa do mundo 2014 na cober-tura do jornalismo esportivo. Revista Eptic. Vol. 18, no 1, janeiro-abril de 2016.

CHARAUDEAU, Patrick e MAINGUENEAU, Dominique. Verbete "Discurso". In: Dicionário de análise do discurso. 2.ed. Trad. Fabiana Komesu et al. São Paulo: Contexto, 2006.

DA MATTA, Roberto. et alii. Universo do Futebol - esporte e sociedade brasileira. Rio de Janeiro: Pinakotheke, 1982.

DUCROT, Oswald. Pressupostos e subentendidos: a hipótese de uma semântica linguística. In: DUCROT, Oswald. O dizer e o dito. Campinas: Pontes, 1987. p. 13-43.

DUNNING, Eric e ELIAS, Norbert. A busca da excitação. $1^{\mathrm{a}}$ ed. 1985. Título original: The Quest for Excitement. Trad.: Maria Manuela Vieira. Lisboa: Difusão Editorial, 1992.

FREYRE, Gilberto. Foot-ball mulato. Diário de Pernambuco, Recife, 17 jun. 1938, p.4.

GUEDES, Simoni Lahud. A produção das diferenças na produção dos 'estilos de jogo' no futebol: a propósito de um texto fundador. In BUARQUE DE HOLLANDA, Bernardo. e BURLAMAQUI, Luiz Guilherme. (Orgs.). Desvendando o jogo - nova luz sobre o futebol. Niterói: Editora da UFF - FAPERJ, 2014.

HALL, Stuart. A identidade cultural na pós-modernidade. Rio de Janeiro: Dp\&a, 1999. Cap. 3, p. 47-65.

HELAL, Ronaldo. Pátria de chuteiras? Como os brasileiros pensam a seleção. Ciência Hoje. N o 314, v. 53, p. 16, maio de 2014.

HELAL, Ronaldo e CABO, Álvaro. (Orgs.). Copa do Mundo: comunicaçâo e identidade cul-tural no país do futebol. Rio de Janeiro: EdUERJ, 2014.

HUIZINGA, Johan. Homo Ludens: o jogo como elemento da cultura. $4^{\mathrm{a}}$ ed. São Paulo: Pers-pectiva, 2000.

LOVISOLO, Hugo e PEREIRA, Camila Augusta. 1938: o nascimento mítico do futebol-arte brasileiro. In: HELAL, Ronaldo e CABO, Álvaro. (Orgs.). Copa do Mundo: comunicação e identidade cultural no pais do futebol. Rio de Janeiro: EdUERJ, 2014. 
MARANHÃO, Thiago. Apolíneos e dionisíacos - o papel do futebol no pensamento de Gil-berto Freyre a respeito do "povo brasileiro". Análise Social. Lisboa, v. 41, n. 179, p. 435-450, 2006.

MARCONDES, Nathalye e MARQUES, José Carlos. A vinheta oficial da FIFA para a Copa do mundo de 2014 e o futebol arte de Gilberto Freyre: aproximaçóes estéticas e apropriação publicitária. Revista Eptic. Vol. 1, no1, janeiro-abril de 2016.

MARQUES, José Carlos. O que é o esporte? As contribuições seminais de Johan Huizinga e Roger Caillois ressignificadas por Roland Barthes. In: VENTURA, Mauro (Org.). Processos midiáticos e produçâo de sentido. São Paulo: Cultura Acadêmica, 2011. P. 157-172.

NYTIMES.COM. Cleaning Up After The World Cup, 2014. Disponível em: <http://www.nytimes.com/2014/07/15/opinion/cleaning-up-after-the-world-cup.html?_r=0>. Acesso em: 28 fev. 2016.

TUBINO, Manoel. O que é esporte? $1^{\text {a }}$ ed. 1993. 1a reimp. São Paulo: Brasiliense, 1999.

VERÓN, Eliseo. El análisis del 'Contrato de Lectura: um nuevo método para los estudios de posicionamento de los suportes de los media. Paris: IREP, 1984. Disponível em: <http://www.catedras.fsoc.uba.ar/delcoto/ textos/veron_eliseo_analisis_del_contrato_de_lectura.pdf $>$. Acesso em: 14 jan. 2016.

\section{Notas}

1. BELO HORIZONTE, Brazil - The fireworks began at dawn. All around this city, loud pops and bangs rag out as men and women and children, so many dressed in yellow, set off flares and beeped car horns. It was supposed to be a magical day. The Brazilian national soccer team, playing at home, was one game away from a World Cup final. No one could have guessed the tears would come before half time. [...] The 2014 World Cup, first plagued by questions about funding and protests and infrastructure and construction, the buoyed by scads of goals and dramatic finishes and a contagious spirit of joy from the local residents, will ultimately be remembered for this: the home team, regarded as the sport's super power, being throttled like an overmatched junior varsity squad that somehow stumbled into the wrong game.

2. PThe final score was Germany 7, Brazil 1. It felt like Germany 70, Brazil 1. [...] "I think", [Luiz Felipe] Scolari said afterward, "that it was the worst day of my life". He was surely not alone in that sentiment. Sports are often a haven of hyperbole, but there was little risk of that here on Tuesday. Given the circumstances and the stakes, this result - a soccer massacre of the highest order - may well be remembered as the most surprising in the World Cup history. [...] "It was the biggest embarrassment of all world cups - 7-1 in a semifinal playing at home?" said Marcel Guimaräes, 38, who traveled to Belo Horizonte from Brasilia. "Not even in a video game". The aftermath of Brazil's defeat could turn ugly. There were reports of a mass robbery at a fan party in Rio de Janeiro and fans setting fire to Brazilian flags in the streets of São Paulo. Local organizers and government officials have been concerned for weeks about the possibility that demonstrations - which have, for the most part, been subdued - would become more intense if Brazil were to be eliminated. Many Brazilians have been upset about the billions of dolars spent on new stadiums and 
other World Cup-related projects. The success of the national team provided a natural balm, but now those emotions may become inflamed. [...] Scolari shrugged then, and trudges out of the news conference room, heading down a narrow hallway. The sunrise fireworks seemed so far away. They had been a rouing beginning, a boisterous start to a day Brazilians hoped they would always remember. Then came a German juggernaut, and a game that a nation of soccer fans can only hope to forget.

3. Those 29 minutes will be scrutinized for generations in Brazil, poked and prodded and dissected the way Bra-zil's dread defeat to Uruguay in the 1950 World Cup final has been. Moacir Barbosa, the Brazilian goalkeeper for that infamous loss, said before he died in 2002 that ever since that game he felt as if he spent the rest of his life in prison. That cell just go more crowded. Every player in a yellow jersey on Tuesday [08 de julho de 2014], many of them superstars, will most likely be defined, and imprisoned, by those 29 minutes.

4. The game began with high hopes. When the music to the national anthem stopped after the require 90 seconds, the Brazilian fans continued singing with vigor, a rousing capella performance. Then, Germany scored early. "I thought we were just in 10 minutes in, we had the entire game ahead", said Gisleine Pedroni, a marketing student who watched at a friend's barbecue in São Paulo. José Brito Lopes, who watched at the bar in a Rio de Janeiro favela where he works, was calm. "When the first goal happened, I thought this was normal, because Germany were playing well", he said. Yet some already had that feeling of dread. The hairs on the neck. The lump in the stomach. "Brazil cannot lose the focus, they have to concentrate", thought Susana Osako, a model who watched the game with her husband in São Paulo. [...] This time [momento do segundo gol da Alemanha], the stadium was more hushed. Two goals in 23 minutes was not necessarily a cause for panic, but it was distressing. A few tears could be seen on faces in the stands. [...] Marcelo, a star defender for Brazil, covered his face with his hands. But in the bleachers, grief had given way to something else, something stranger. "We started to laugh the situation", said Felipe Seligman, 30, who was wearing the same Brazil shorts and zip-up jacket that he wear every time Brazil plays. "We were saying, 'Oh my god, what's going on, what's happening? It's real?' ". The fifth goal was when Machado forced himself to turn away from the screen. "I kept listening to the game, listening only because I could no longer watch it", he said. Three goal in four minutes. Four goals in six minutes. Five goals in 29 minutes. One country could not believe what had just happened.

5. Brazil can be proud of the World Cup it held-except, of course, the shocking breakdown of its national team in the 7-1 semifinal loss to Germany. The crowds were colorful, loud and behaved, and the play ranged from entertaining to utterly brilliant, all devoured by record-breaking audiences on television and social media. There were the dodgy calls, blatant flops and Luis Suarrez's bizarre bite, but the perfect score by Mario Gotze, which gave the Cup to Germany, is the more accurate icon of the four-and-half-week tournament. In all, the World Cup demonstrated why football, a.k.a. soccer, is the most global and popular of sports. And why it is time for FIFA to measure up to the sport it governs. [...] Soccer is a hugely important force in the world today. It stewards should do everything in their power to keep it clean, safe and fair 